\title{
Fournier's gangrene: a retrospective review of management outcomes and seasonal variations of clinical presentation
}

\author{
Ikenna I. Nnabugwu ${ }^{*}$ (D), Okechukwu O. Onumaegbu ${ }^{2}$ and Louis T. Okolie
}

\begin{abstract}
Background: To review retrospectively the outcomes of management of Fournier's gangrene (FG) and to assess for possible seasonal variations in clinical presentations of FG to a referral hospital in a tropical African country.

Methods: The medical records of patients who presented with FG from February 2012 to December 2019 were reviewed. Of interest were age of patient, vital signs at presentation, site of gangrene, duration of hospital admission, and management interventions deployed. Analysis was with SPSS ${ }^{\circledR}$ version 21.

Results: Twenty-three of 28 medical records could be analyzed. Median Fournier's Gangrene Severity Index (FGSI) was 5 (IQR:3-10), the median Uludag-FGSI (UFGSI) was 7 (IQR:4-14). In 82.6\%, the scrotum was the site of onset; in 8.7\%, the lesion had spread beyond the pelvis. Diabetes mellitus (30.4\%), HIV infection (13.0\%) and nephropathy (17.4\%) were identified co-morbidities. There were $2.4 \pm 1.0$ debridement sessions and $1.5 \pm 1.3$ transfused units of blood per patient. In 60.9\%, the wound edges were undermined and apposed; in 17.4\%, split skin grafting or fasciocutaneous flap cover was deployed. In 17.4\%, satisfactory wound closure needed more than 1 theater session. Mean duration of hospital admission was $51.4 \pm 19.4$ days. No mortality was recorded.

Majority (91.2\%) presented in hot, dry months of October through March with peak in December. No case presented in the wet months of May through September.

Conclusion: Meager resources notwithstanding, FG management outcomes are generally satisfactory. Furthermore, FG is observed to present mostly in the hot, dry months of the year in the 8 years under review.
\end{abstract}

Keywords: Challenges of management, Fournier's gangrene, Outcomes, Seasonal variation

\section{Background}

Fournier's gangrene (FG) is a synergistic bacterial infection affecting usually the external genitalia, perianal area, or perineum causing rapidly progressing tissue death $[1$, 2]. In this synergistic infection, the aerobic bacterial invasion of tissue creates the needed anaerobic environment for anaerobic bacterial habitation and multiplication [2]. The resultant local tissue destruction and gangrene

\footnotetext{
*Correspondence: ikenna.nnabugwu@unn.edu.ng

${ }^{1}$ Urology Unit, Department of Surgery, College of Medicine, University

of Nigeria Ituku-Ozalla, PMB 01129, Enugu, Nigeria

Full list of author information is available at the end of the article
}

as well as systemic toxicity are consequent upon the combined invasive and toxic activities of the bacterial organisms.

Classically, FG was described as spontaneous in onset in young males who were otherwise normal [3]. However, recent studies have consistently shown that predisposing conditions such as diabetes mellitus (DM), urethral stricture, or other causes of bladder outlet obstruction, and suppurating perianal lesions are usually recognizable in many cases of FG [1]. In addition, FG is seen more in low- and middle-income countries (LMIC), especially among persons of low socioeconomic status [4]. 
In LMIC, late presentation to appropriate healthcare facility for many disease conditions is known to be prevalent $[5,6]$. Fournier's gangrene is not an exception, and achieving wound cover is one of the many challenges associated with management of the lesion encountered in such late-presentation. Increased burden of care occurs in terms of repeated debridement sessions in the septic theater, blood transfusions, as well as in terms of prolonged period of wound dressing, high dependency unit (HDU) admission, and overall hospital admission. Beyond these, achieving prompt, functional and acceptable wound cover could pose real challenge.

There may be seasonal variation in the incidence of FG. The work of Ullah et al. from Pakistan shows that a greater proportion of patients presented in the hot humid period of the year [4]. Hot weather conditions from sunlight may impair skin integrity and may depress skin immunity through a number of possible skin immune cell mediated mechanisms [7]. Southeastern Nigeria experiences dry hot season from the month of October through the month of April. Within this period, the months of December and January are relatively cold at night but very dry due to low humidity wind from the Sahara Desert [8]. In contrast to this dry season, the rest of the year is wet and humid due to rainfall. The skin suffers differing fates in these two seasons.

The aim of this study is to retrospectively identify the management outcomes and the seasonal variation in clinical presentation for Fournier's gangrene cases in a tropical African setting.

\section{Methods}

Hospital records of a tertiary health institution in southeastern Nigeria were reviewed retrospectively from February 2012 through December 2019, for cases of Fournier's gangrene presentation and management. Diagnosis of FG was based on clinical history and physical examination findings.

As part of standard of care, urinary diversion was done by urethral catheterization or by suprapubic cystostomy. Wound debridement sessions were undertaken under regional analgesia in the septic theater while wound dressings were done in the wards. Sodium hypochlorite solution or virgin honey was used as desloughing agent in dressing the wounds. All patients had systemic broadspectrum antibiotic therapy targeting both aerobes and anaerobes. Blood was transfused when necessary. All wound closure procedures were done in theater under appropriate analgesia as well.

Variables of interest from each patient's medical record were age and gender of patient, month of presentation in the year, primary site of the lesion and extent of spread, as well as maximum body temperature, heart rate, and respiratory rate recorded on admission in the hospital during the course of illness. In addition, the packed cell volume (PCV), the white blood cell count (WBC), and the serum concentrations of sodium ion $\left(\mathrm{Na}^{+}\right)$, potassium ion $\left(\mathrm{K}^{+}\right)$, bicarbonate ion $\left(\mathrm{HCO}_{3}{ }^{-}\right)$, and creatinine $(\mathrm{Cr})$ were retrieved in addition to the Fournier's Gangrene Severity Index (FGSI) and Uludag Fournier's Gangrene Severity Index (UFGSI) calculated for each of the patients [3, 9]. Furthermore, the duration of admission in the critical care unit, the number of debridement sessions in theater, the number of units of blood transfused, the wound cover technique adopted subsequently and the duration of hospital admission were noted. Finally, the outcome of treatment in the short term was noted.

Cases of scrotal abscess or peri-anal abscess that were not associated with obvious tissue gangrene were excluded from this study. Descriptive statistics and other analyses were done using SPSS $^{\circledR}$ version 21 (IBM Co., Armonk, NY, USA). The Hospital Bioethics Committee gave clearance (NHREC/05/01/2008B-FWA00002458$1 \mathrm{RB} 00002323)$ for this retrospective review.

\section{Results}

There were 28 FG presentations. The medical records of 5 of these patients lack documentations on many of the variables of interest and were excluded from further analysis. All 23 patients were male Nigerians. Three patients had suprapubic cystostomy, while the rest had urethral catheterization to divert urine and to ease wound care. Eighteen $(78.3 \%)$ patients required 2 or more debridement sessions to achieve loco-regional control of infection. Hyperbaric oxygen therapy was not used in the care of the wound. Blood was transfused in $65.2 \%$ of presentations. Colostomy was not required in any patient. Four patients (17.4\%) required more than one wound closure sessions. Vacuum-assisted closure (VAC) of the postdebridement tissue defect was not deployed in any of the patients. There was no mortality recorded. One patient was discharged on request, but against medical advice, during the wound dressing phase. Table 1 shows a summary of the clinical characteristics of the patients, while Table 2 is a summary of the features of the lesions at presentation, the observed co-morbidities and the wound closure techniques.

Figure 1 (Inset 1) shows FG lesion requiring emergency debridement for loco-regional control of infection, while Fig. 1 (Inset 2) shows post-debridement wound undergoing wound dressing. 
Table 1 Summary of the clinical characteristics of patients with FG managed from 2012-2019 ( $n=23)$

\begin{tabular}{|c|c|c|c|}
\hline Variable & Range & Median (IQR) & Mean (SD) \\
\hline Age (years) & $16.0-85.0$ & $53.0(45.0-69.0)$ & $54.7(18.4)$ \\
\hline Maximum Temperature $\left({ }^{\circ} \mathrm{C}\right)$ & $36.5-39.2$ & $37.5(36.9-38.5)$ & $37.7(0.8)$ \\
\hline Heart Rate (/sec) & $76.0-160.0$ & $94.0(86.0-112.0)$ & $99.9(19.7)$ \\
\hline Respiratory Rate (/sec) & $17.0-32.0$ & $22.0(20.0-28.0)$ & $23.4(4.0)$ \\
\hline PCV (\%) & $22.0-39.0$ & $27.0(24.0-33.0)$ & $28.3(5.1)$ \\
\hline Units of Blood Transfused & $0.0-4.0$ & $2.0(0.0-2.0)$ & $1.5(1.3)$ \\
\hline WBC (cells/ml) & $4,510-28,000$ & $12,220(8,900-17,200)$ & $13,686(6,157)$ \\
\hline $\mathrm{Na}+(\mathrm{mmol} / \mathrm{L})$ & 110.0-149.0 & $133.0(130.0-140.0)$ & $132.6(11.0)$ \\
\hline $\mathrm{K}+(\mathrm{mmol} / \mathrm{L})$ & $2.9-4.9$ & $3.9(3.5-4.2)$ & $3.9(0.6)$ \\
\hline $\mathrm{HCO} 3-(\mathrm{mmol} / \mathrm{L})$ & $19.0-32.3$ & $22.0(20.0-25.5)$ & $23.0(3.7)$ \\
\hline Creatinine (mg/dl) & $0.6-10.0$ & $1.3(1.1-1.7)$ & $2.1(2.1)$ \\
\hline FGSI & $0.0-15.0$ & $5.0(3.0-10.0)$ & $6.0(4.2)$ \\
\hline UFGSI & $2.0-17.0$ & $7.0(4.0-14.0)$ & $8.1(4.9)$ \\
\hline Number of Debridement Sessions & $1.0-4.0$ & $2.0(2.0-3.0)$ & $2.4(1.0)$ \\
\hline Duration of Hospital Admission (days) & $15.0-82.0$ & $48.5(38.3-68.8)$ & $51.4(19.4)$ \\
\hline
\end{tabular}

Table 2 Summary of the characteristics of the presenting lesions and the wound closure techniques

\begin{tabular}{ll}
\hline Variable & Frequency (\%) \\
\hline Site of onset of lesion & $19(82.6)$ \\
Scrotum & $3(13.0)$ \\
Peri-anal area & $1(4.3)$ \\
Penile shaft & \\
Extent of spread (Dissemination) & $16(69.6)$ \\
Urogenital/Anorectal region & $5(21.7)$ \\
Pelvic region & $2(8.7)$ \\
Beyond pelvic region & \\
Co-morbid conditions & $7(30.4)$ \\
Diabetes mellitus & $4(17.4)$ \\
Nephropathy & $3(13.0)$ \\
HIV positive & $5(21.7)$ \\
Hypertension & \\
Precipitating Factors & $2(8.7)$ \\
Urethral stricture & $1(4.3)$ \\
Fissure-in-ano & \\
Wound closure technique & $4(17.3)$ \\
Spontaneous closure & $14(60.9)$ \\
Undermine and appose & $2(8.7)$ \\
Split skin grafting & $2(8.7)$ \\
Flap cover &
\end{tabular}

Of the 23 patients, $4(17.4 \%)$ presented in the month of October, 4 (17.4\%) in November, 7 (30.4\%) in December, $3(13.0 \%)$ in January, 2 (8.7\%) in February and 1 (4.3\%) each in March, April and June. There was no case of FG presenting in the months of July through September. Depicted in Fig. 2 is the monthly distribution of cases of FG presenting in the period under review.

\section{Discussion}

Similar to more recent studies reporting that FG tends to affect older persons $[3,10]$, the mean age of patients from this study is $54.7 \pm 18.4$ years (Table 1 ), a value slightly higher than the mean age from previous review from this same healthcare facility [11]. Though this disease condition is not restricted to males, all patients managed in this series are males. Generally, male preponderance however is not in contention $[3,9,12]$. Managing FG could be quite challenging. The mean duration of hospital admission is $51.4 \pm 19.4$ days, within which there is a mean $2.4 \pm 1.0$ debridement sessions in septic theater, and transfusion of a median of 2 (IQR 0-2) units of blood (Table 1). Though the mean duration of hospital admission appears higher from this current review compared to our earlier review [11], the range remains essentially similar. Like many other studies $[13,14]$, this study reveals that typically, 2 or more debridement sessions are needed per patient presenting with FG to achieve locoregional control of the infection. This is possibly because the fate and the extent of already damaged tissue adjoining the obviously gangrenous tissue becomes clearer 24-48 h post-initial debridement.

Tissue gangrene as observed on the skin is generally a lot less on the skin than the connective tissue beneath the skin. The implications of this are that the systemic inflammatory response consequent upon the lesion is enormous, and with the subsequent containment of the disease following radical debridement session(s), the resultant wound requiring closure covers a wide area. Sometimes, there appears to be some evidence of the patient's immunity attempting to wall off the rampaging infection as shown in Fig. 1 (inset 1), but this attempt is usually not to be relied upon during pre-debridement 

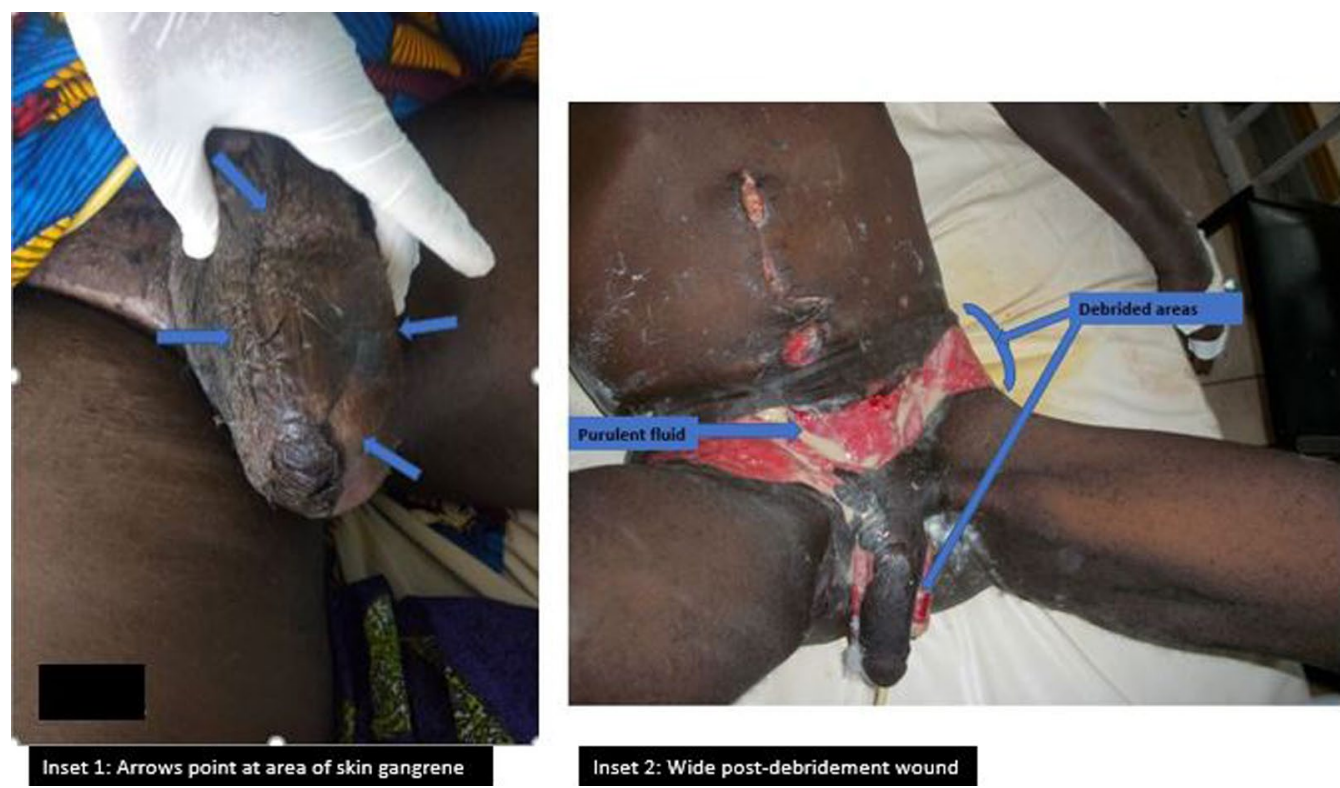

Fig. 1 (Inset 1) shows Fournier's gangrene involving the scrotum; (Inset 2) shows lower abdominal and scrotal wound post-debridement of extensive Fournier's gangrene

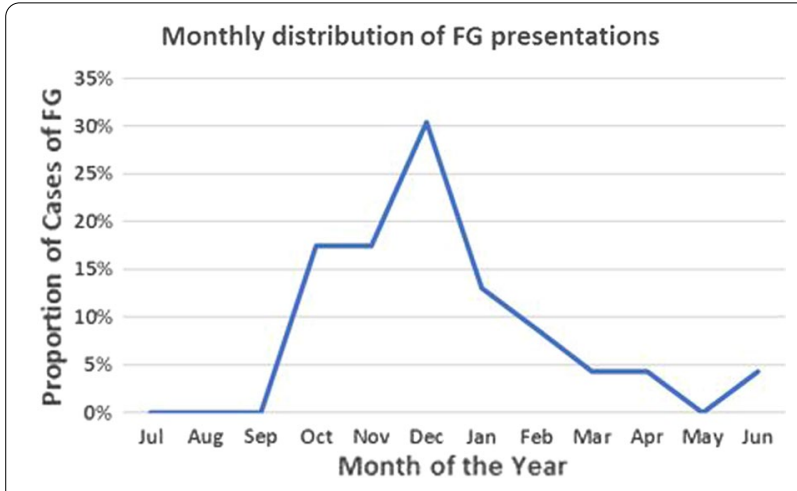

Fig. 2 The monthly distribution of clinical presentations to hospital with Fournier's gangrene from February 2012 to December 2019

decision-making. Figure 1 (inset 2) shows near complete loss of scrotal tissue and a wide area of lower abdominal skin and subcutaneous tissue loss post-debridement. Lesions such as shown in Fig. 1 (inset 2) are not uncommon in our low socioeconomic setting and achieving wound closure in these lesions surely pose some challenges.

The median FGSI and UFGSI of 5 (IQR 3-10) and 7 (4-14), respectively, from this series are lower than values obtained from series that report mortalities [10, 15-17]. It can be inferred therefore, that the metabolic derangements in the patients reviewed in this series are generally less severe. The occasionally observed attempt at tissue "demarcation" pre-debridement appears to be in line with less severe metabolic derangements. This finding also lends credence to leanings on FGSI and UFGSI as indices of disease severity and possibly mortality from FG [15-18]. At $65.2 \%$ of patients, the rate of transfusion of blood or blood components in this series is similar to rates from some other studies from northern Nigeria [19] and from Africa [16].

Most (78.3\%) patients presenting with FG needed at least two theater sessions: one for debridement and another for wound closure. Obviously, each theater session has its risks and challenges. With adequate postdebridement wound care, a good number of the wounds could be closed by undermining and apposing the wound edges [14]: about $61 \%$ of the wounds post-debridement in this series could be closed as such (Table 2). However, complex reconstructive procedures are deployed sometimes to close very large wounds [13, 15]. For instance, the lesion in Fig. 1 (inset 2) required a combination of random fascio-cutaneous flap and split skin graft to achieve wound cover. The less complex the wound cover technique deployed, the less the risk of post-cover complications and the less the risk for further theater sessions to accomplish functionally acceptable outcome.

Beyond the earlier reports on Fournier's gangrene in the late nineteenth century which described lesions that developed spontaneously apparently without any predisposing condition, more recent reports describe lesions with recognizable predisposing and precipitating factors. 
$[3,10]$ Predisposing conditions such as diabetes mellitus, human immunodeficiency virus disease and other causes of immunosuppression have been described quite frequently in FG, $[16,18]$ and about half of the patients in this review have some predisposing condition. On the other hand, the possibility of an association between particular seasons of the year and FG in tropical climate has not been brought to the fore. In southeastern Nigeria, the months of October through March are usually dry and hot: interestingly, $91.2 \%$ of the FG patients in this 8 year review presented within this dry and hot period (Fig. 2).

There are recognized seasonal variations in some infective diseases such as influenza [20, 21], epidemic retinitis [22], measles, [23], and bacterial meningitis [24]. The observed seasonal variations in rates of these infections have been attributed to factors such as variations in humidity, in level of immunity and in availability of wholesome water for domestic activities. The link between FG and dry hot season as observed from this review is not particularly clear. However, it is possible that the dry weather may result in minute cracks in the skin, [8] and the hot weather may support bacterial proliferation and virulence [25] as well as cause skin immunosuppression. [7] The low-humidity harmattan winds prevalent in the months of December and January result in particularly dry and harsh weather recognized as risk for cracks in the skin of some parts of the body such as the heel and the lips [8]. If such minute skin breeches occur in the scrotal skin, it could predispose to FG. Recognizing that only $3(13.0 \%)$ patients in this review (Table 2) had loco-regional precipitating factors ( 2 neglected urethral stricture and 1 fissure-in-ano), the role of minute skin breeches cannot be ignored. Such minute skin breeches could explain the preponderance of FG with no obvious precipitating factor.

A limitation of this retrospective study is the absence of report on causative microorganisms. This is so because anaerobic culture does not form part of conventional wound swab for culture in our services.

\section{Conclusion}

This review shows that, regarding the median FGSI and the median UFGSI, there may be less severe metabolic derangements on the average, among patients presenting with FG in our setting. Despite resource limitations, outcome is generally satisfactory. No mortality is recorded, but large post-debridement wounds pose some management challenges. Recognizable loco-regional precipitating factors such as fissure-in-ano, perianal fistula, urethrocutaneous fistula are uncommon, but co-morbid conditions such as DM, HIV infection are frequently identified. Fournier's gangrene is seen mostly in the hot dry months suggesting that FG may be a seasonal infection.

\section{Abbreviations}

FG: Fournier's gangrene; DM: Diabetes mellitus; LMIC: Low-and-middleincome countries; HDU: High dependency unit; FGSI: Fournier's Gangrene Severity Index; UFGSI: Uludag Fournier's Gangrene Severity Index.

\section{Acknowledgements}

The authors are grateful to Solomon Anyimba and Chinwe Nnabugwu for their contributions in gathering the data and preparing the manuscript.

\section{Authors' contributions}

IIN contributed in conception, study design, data acquisition and analysis, drafting of manuscript, revision of the draft manuscript. $\bigcirc 0 \bigcirc$ contributed in conception, study design, data acquisition, revision of the draft manuscript. LTO contributed in data acquisition and analysis, drafting of manuscript, revision of the draft manuscript. All authors approved of the final draft of the manuscript being submitted.

Funding

The authors received no external sources of funding for this research work or for publishing the findings therein.

\section{Declarations}

\section{Ethics approval and consent to participate}

The University of Nigeria Teaching Hospital Bioethics Committee gave clearance (NHREC/05/01/2008B-FWA00002458-1RB00002323) for this retrospective review.

\section{Availability of data and material}

Data in support of this manuscript is available at Mendeley Data Repository [http://dx.doi.org/10.17632/tdrkkcnzv3.1].

\section{Competing interests}

The authors declare that there are no competing interests.

\section{Author details}

${ }^{1}$ Urology Unit, Department of Surgery, College of Medicine, University of Nigeria Ituku-Ozalla, PMB 01129, Enugu, Nigeria. ${ }^{2}$ Plastic Surgery Unit, Department of Surgery, College of Medicine, University of Nigeria Ituku-Ozalla, PMB 01129 , Enugu, Nigeria.

Received: 10 November 2020 Accepted: 15 April 2021

Published online: 23 April 2021

References

1. Singh A, Ahmed K, Aydin A, Khan MS, Dasgupta P (2016) Fournier's gangrene: a clinical review. Arch Ital Urol Androl 88(3):157-164. https://doi. org/10.4081/aiua.2016.3.157

2. Castillejo Becerra CM, Jaeger CD, Rose JR, Beecroft NJ, Shah NC, Posid T, Jenkins LC, Baradaran N (2020) Microorganisms and antibiogram patterns in Fournier's gangrene: contemporary experience from a single tertiary care center [published online ahead of print, 2020 Jun 30]. J Urol. https:// doi.org/10.1097/JU.0000000000001194

3. Luján Marco S, Budía A, Di Capua C, Broseta E, Jiménez CF (2010) Evaluation of a severity score to predict the prognosis of Fournier's gangrene. BJU Int 106(3):373-376. https://doi.org/10.1111/j.1464-410X.2009.09075.x

4. Ullah S, Khan M, Jan MAU (2009) Fournier's gangrene: a dreadful disease. Surgeon 7(3):138-142. https://doi.org/10.1016/s1479-666x(09)80036-x

5. Fatunmbi M, Saunders A, Chugani B, Echeazu I, Masika M, Edge S, Nwogu C (2019) Cancer registration in resource-limited environments: experience in Lagos, Nigeria. J Surg Res 235:167-170. https://doi.org/10.1016/j. jss.2018.09.021 
6. Brand NR, Qu LG, Chao A, Ilbawi AM (2019) Delays and barriers to cancer care in Low- and Middle-Income Countries: a systematic review. Oncologist 24(12):e1371-e1380. https://doi.org/10.1634/theoncologist. 2019-0057

7. González Maglio DH, Paz ML, Leoni J (2016) Sunlight effects on immune system: Is there something else in addition to UV-induced immunosuppression? Biomed Res Int 2016:1934518. https://doi.org/10.1155/2016/ 1934518

8. Sufiyan I, Mohammed KD, Bello IE, Zaharadeen I (2020) Impact of harmattan season on human health in Keffi, Nasarawa State Nigeria. Matrix Sci Medica 4:44-50. https://doi.org/10.4103/MTSM.MTSM_1_20

9. Yilmazlar T, Ozturk E, Ozguc H, Ercan I, Vuruskan H, Oktay B (2010) Fournier's gangrene: an analysis of 80 patients and a novel scoring system. Tech Coloproctol 14(3):217-223. https://doi.org/10.1007/s10151-010-0592-1

10. Garg G, Singh V, Sinha RJ, Sharma A, Pandey S, Aggarwal A (2019) Outcomes of patients with Fournier's gangrene: 12-year experience from a tertiary care referral center. Turk J Urol 45(Supp. 1):S111-S116. https://doi. org/10.5152/tud.2019.39586

11. Ugwumba FO, Nnabugwu II, Ozoemena OF (2012) Fournier's gangreneanalysis of management and outcome in south-eastern Nigeria. S Afr J Surg 50(1):16-19

12. Ballard DH, Mazaheri P, Raptis CA, Lubner MG, Menias CO, Pickhardt PJ, Mellnick VM (2020) Fournier gangrene in men and women: appearance on CT, Ultrasound, and MRI and what the surgeon wants to know [published online ahead of print, 2020 Jan 28]. Can Assoc Radiol J. https://doi. org/10.1177/0846537119888396

13. Louro JM, Albano M, Baltazar J, Vaz M, Diogo C, Ramos S, Cabral L (2019) Fournier's gangrene: 10-year experience of a plastic surgery and burns department at a tertiary hospital. Acta Med Port 32(5):368-374. https:// doi.org/10.20344/amp.11003

14. Sockkalingam VS, Subburayan E, Velu E, Rajashekar ST, Swamy AM (2018). Fournier's gangrene: prospective study of 34 patients in South Indian population and treatment strategies. Pan Afr Med J 31:110. https://doi. org/10.11604/pamj.2018.31.110.15495

15. Egin S, Kamali S, Hot S, Gökçek B, Yesiltas M (2020) Comparison of mortality in Fournier's gangrene with the two scoring systems. J Coll Phys Surg Pak 30(1):67-72. https://doi.org/10.29271/jcpsp.2020.01.67

16. Elsaket AE, Maharajh S, Urry RJ (2018) The presentation, management and outcomes of Fournier's gangrene at a tertiary urology referral centre in
South Africa. S Afr Med J 108(8):671-676. https://doi.org/10.7196/SAMJ. 2018.v108i8.13100

17. Wetterauer C, Ebbing J, Halla A, Kuehl R, Erb S, Egli A, Schaefer DJ, Seifert $\mathrm{HH}$ (2018) A contemporary case series of Fournier's gangrene at a Swiss tertiary care center-can scoring systems accurately predict mortality and morbidity? World J Emerg Surg 13:25. https://doi.org/10.1186/ s13017-018-0187-0

18. Arora A, Rege S, Surpam S, Gothwal K, Narwade A (2019) Predicting mortality in Fournier gangrene and validating the Fournier gangrene severity index: Our experience with 50 patients in a tertiary care center in India. Urol Int 102(3):311-318. https://doi.org/10.1159/000495144

19. Aliyu S, Ibrahim AG, Ali N, Waziri AM. Fournier's gangrene as seen in University of Maiduguri Teaching Hospital. ISRN Urol. 2013; 2013: 673121. Published 2013 Aug 12. https://doi.org/10.1155/2013/673121

20. Barr IG, Deng YM, Grau ML, Han AX, Gilmour R, Irwin M et al (2019) Intense interseasonal influenza outbreaks, Australia, 2018/19. Euro Surveil 24(33):1900421. https://doi.org/10.2807/1560-7917.ES.2019.24.33.19004 21

21. Nisar N, Badar N, Aamir UB, Yaqoob A, Tripathy JP, Laxmeshwar C et al (2019) Seasonality of influenza and its association with meteorological parameters in two cities of Pakistan: a time series analysis. PLoS ONE 14(7):e0219376. https://doi.org/10.1371/journal.pone.0219376

22. Kawali A, Srinivasan S, Mahendradas P, Shetty B (2020) Epidemic retinitis and community outbreaks. Indian J Ophthalmol 68(9):1916-1919. https:// doi.org/10.4103/ijo.IJO_1327_20

23. Faruk AS, Adebowale AS, Balogun MS, Taiwo L, Adeoye O, Mamuda S, Waziri NE (2020) Temporal trend of measles cases and impact of vaccination on mortality in Jigawa State, Nigeria, 2013-2017: a secondary data analysis. Pan Afr Med J 35(Suppl 1):13. https://doi.org/10.11604/pamj. supp.2020.35.1.19780

24. Kaburi BB, Kubio C, Kenu E, Ameme DK, Mahama JY, Sackey SO, Afari EA (2017) Evaluation of bacterial meningitis surveillance data of the northern region, Ghana, 2010-2015. Pan Afr Med J 27:164. https://doi.org/10. 11604/pamj.2017.27.164.11036

25. Miller R, Pywell S, Chan J, McCluney S, Halsey T (2019) Seasonal variation in hand and upper limb soft tissue infections. J Hand Surg Asian Pac 24(2):189-194. https://doi.org/10.1142/S2424835519500255

\section{Submit your manuscript to a SpringerOpen ${ }^{\odot}$ journal and benefit from:}

- Convenient online submission

- Rigorous peer review

- Open access: articles freely available online

- High visibility within the field

- Retaining the copyright to your article

Submit your next manuscript at $\boldsymbol{\nabla}$ springeropen.com 